besser machen. Gleichwohl handelte mit Guttenberg, der alle Popularitätsumfragen, aber noch nie eine Wahl gewonnen hat, zum ersten Mal ein neuer Typus im Sinn Max Webers: Ein Politiker, der sich nahezu vollständig auf medial vermittelte (und erzeugte) Zustimmung stützt und nicht auf jene seiner Parteigremien (Schröder war insoweit nur ein Anfänger). Vielleicht ist das die wichtigste der zahlreichen Veränderungen, die der sehr gelungene Band nachvollziehbar macht.

\title{
Vorerst gescheitert
}

\author{
Johannes Staemmler
}

Rezension von Karl-Theodor zu Guttenberg und Giovanni di Lorenzo (2011). Vorerst gescheitert. Herder.

„Lieber inkompetent als schuldig“ titelte Der Spiegel über Robert Murdoch, der versuchte, sich aus der Abhör-Affäre seiner Boulevard-Blätter in England herauszuwinden. Der Titel passt aber nicht weniger gut auf ein Buch, das einige qua seiner Existenz für ein Ärgernis halten. In Vorerst gescheitert reden der ehemalige Verteidigungsminister zu Guttenberg und der ZEIT-Chefredakteur di Lorenzo über alles, was $2011 \mathrm{im}$ Leben des heutigen Privatiers zu Guttenberg passiert ist, wie es dazu kam und was daraus wird.

Der einst beliebteste Politiker Deutschlands trat am 3. März 2011 von seinen Ämtern mit der Begründung zurück, er halte dem öffentlichen Druck nicht mehr stand und fühle sich am Ende seiner Kräfte. Die Debatte drehe sich, so der Minister, nur noch um Fehler von ihm aus der Vergangenheit und nicht um die Soldaten, die in Afghanistan kämpften und auch stürben. Zu Guttenberg verließ das Land.

Das Buch beginnt gleich mit den Fragen, die damals offen blieben. Haben sie betrogen, Herr Guttenberg? Und damit beginnt ein Reigen verwundener Fabulierungen, in denen der zu Guttenberg den Vorwurf des Vorsatzes von sich weist. Er begründet die Vielzahl nicht zitierter fremder Texte (ergo Plagiate) mit der ebenso unfassbaren Anzahl an Datenträgern, die ihn während der Arbeit begleiteten und über die er den Überblick verlor. Diese sich über viele Jahre hinziehende Arbeit sei eine „Dummheit“ gewesen, deren Abschluss er selbst auf ein gewisses Maß an „Hochmut“ zurückführt. Hätte er betrügen wollen, dann hätte er es cleverer gemacht. Dem Leser bleibt die Wahl zwischen Regen und Traufe auf der Suche nach einer schlüssigen Erklärung.

Bevor der Frage nachgegangen wird, ob der Wissenschaftler zu Guttenberg und der derzeit außer Dienst stehende Politiker zur selben Persönlichkeit gehören, sei noch eine Bemerkung in eigener Sache erlaubt. Als die Debatte um die Doktorarbeit des Ministers abzuflauen drohte, formulierten Doktoranden in Berlin einen Offenen Brief an die Kanzlerin mit der Bitte, sich in dieser Sache genauer zu erklären. Sie fürchteten darum, dass nicht nur alle mühsame wissenschaftliche Kleinarbeit zur Makulatur werden könnte, sondern dass der gesamte Wissenschaftsstandort Deutschland sich als FeelGood-Thema ohne Substanz entpuppt. Innerhalb kürzester Zeit versammelten sich 60.000 Menschen mit ihren Unterschriften unter diesem Brief als Signal ihrer Empörung.
Auf Seite 47 lässt der Privatier nun ungewollt einen Einblick auf sein Wesen zu. Es hätte ihm tatsächlich erst sehr spät gedämmert, dass sich irgendwer durch sein Handeln gekränkt gefühlt haben könnte. Schließlich müsse man aber bedenken, dass er seine Arbeit unter anderen Ausgangsbedingungen geschrieben habe. Das Ringen um Mitleid nimmt seinen Lauf.

Diese Haltung steht beispielhaft für weite Teile des Buches, in dem der Satz „Ich würde es wieder genauso machen.“ der häufigste ist. Wir begegnen einem Süchtigen, dem die Drogen Aufmerksamkeit und Gehorsam entzogen wurden. Herr zu Guttenberg fordert - er bittet nicht - Fairness in der Bewertung seiner Handlungen. Er begründet rational, warum er auf dem Broadway oder als Kampfjetpilot posierte. Auch spricht er von sich als prinzipienfest und mutig, im Stillen auch nachdenklich und vor allem den Menschen zugewandt und bereit, ihnen beim Tragen ihrer Bürden zu helfen. Er redet über sich als einen, dem das ungefragt Helfen in die Wiege gelegt wurde und der gar nicht anders kann, als im Rampenlicht zu stehen, zum Besten der anderen.

In der Verbindung seines eigenen Wohls mit dem Wohl der Bürger gelingt es ihm, Mitgefühl beim Leser zu erzeugen. Man erwischt sich dabei, ihm glauben zu wollen, dass er das Beste wollte. Und genau darin liegt die Gefahr zumindest des Buches. Giovanni di Lorenzo schafft es nicht, das Erlösungsversprechen offensichtlich $\mathrm{zu}$ machen. Er versucht ihn $\mathrm{zu}$ bedrängen, erliegt ihm aber am Ende selbst. Der Leser wünscht sich schließlich, dass zu Guttenberg zurückkommt, denn dann geht es dem Freiherrn besser und dem Leser auch. Auch lässt er sein politisches Programm durchschimmern, wenn er explizit das Unbehagen mit „Führung“ für beendet erklärt und stattdessen heraushebt, dass von Deutschland Führung erwartet würde. „Wir müssen es nur geschickt und klug machen (...) “ (S. 165).

Es steht nach der Lektüre des Buches außer Zweifel, dass Herr zu Guttenberg die politische Bühne wieder betreten wollen wird. Er braucht sie und lebt von ihrer Aufmerksamkeit. Nur lässt es seine Persönlichkeit nicht zu, sich in Demut über sein Handeln zu üben. Das Buch legt schillernd aber klar offen, auf was wir uns dann einstellen müssen. Es ist eine Lektüre, die, wenn man sie einrahmt mit Werken Webers, Freuds und Shakespeares, sich zum unfertigen Skript einer düsteren Heldensage verdichtet. Bleibt anzukündigen, dass wir Wissenschaftler alles tun werden, um ihre Vollendung zu verhindern. 